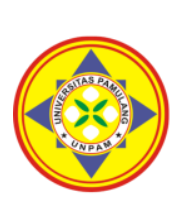
PERKUSS

\title{
PENGARUH LINGKUNGAN KERJA DAN KOMPENSASI TERHADAP KINERJA KARYAWAN PADA PT. INDOMARCO PRISMATAMA AREA KOTA DEPOK
}

\author{
${ }^{1}$ Rahidi, 2*Muger Apriansyah \\ Universitas Pamulang, Tangerang, Banten, Indonesia \\ *dosen01019@unpam.ac.id
}

\begin{abstract}
Abstrak
Tujuan dalam penelitian ini adalah untuk mengetahui berapa besar pengaruh lingkungan kerja terhadap kinerja karyawan pada PT Indomarco Prismatama, untuk mengetahui berapa besar pengaruh kompensasi terhadap kinerja karyawan pada PT. INDOMARCO PRISMATAMA dan untuk mengetahui berapa besar pengaruh lingkungan kerja dan kompensasi terhadap kinerja karyawan pada PT. INDOMARCO PRISMATAMA. Metode yang digunakan pada penelitian ini yaitu metode kuantitatif, melalui pendekatan, pengumpulan data dan analisa menggunakan statistic. Data yang digunakan melalui teknik observasi, angket atau kuesioner sebanyak 70 responden dengan menggunakan teknik sampling jenuh. Metode analisa yang digunakan dalam penelitian ini adalah uji validitas, uji realibilitas, uji normalitas, uji Multikolinearitas, uji autokorelasi, uji Heteroskedastisitas, uji regresi linear berganda, uji koefisien korelasi, uji determinasi dan uji signifikan (uji t dan uji f). Hasil penelitian dapat disimpulkan bahwa variabel Lingkungan Kerja (X1) dan Kompensasi (X2) Terhadap Kinerja Karyawan (Y) berpengaruh Kuat yaitu sebesar 79,5\% sisanya 20,5\% dipengaruhi oleh faktor lain diluar penelitian ini.
\end{abstract}

Kata Kunci: Lingkungan Kerja, Kompensasi, Kinerja

\section{Abstract}

The purpose of this study was to determine how much influence the work environment has on employee performance at PT. INDOMARCO PRISMATAMA, to determine how much influence compensation has on employee performance at PT. INDOMARCO PRISMATAMA and to determine how much influence the work environment and compensation have on employee performance at PT. INDOMARCO PRISMATAMA. . The method used in this research is quantitative method, namely through the approach, data collection and analysis using statistics. The data used through observation techniques, questionnaires or questionnaires as many as 70 respondents using saturated sampling technique. The analysis method used in this research is validity test, reliability test, normality test, multicollinearity test, autocorrelation test, heteroscedasticity test, multiple linear regression test, correlation coefficient test, determination test and significant test ( $t$ test and $f$ test). The results showed that can be concluded that the Work Environment (X1) and Compensation (X2) variables on Employee Performance $(Y)$ have a strong effect, namely the remaining $79.5 \% 20.5 \%$ is influenced by other factors outside of this study.

Keywords: Work Environment, Compensation, Performance

\section{PENDAHULUAN}

Lingkungan kerja yang baik meliputi beberapa aspek yang harus diperhatikan misalnya ruang kerja yang nyaman, kondisi kerja yang aman, suhuruangan yang tetap, pencahayaan yang yang memadai hubungan dengan rekan kerja yang baik. Jika hal tersebut terpenuhi oleh suatu perusahaan maka akan menimbulkan tingkat kepuasan karyawan dan akan meningkatkan kinerja karyawan.dapat diketahui standar lingkungan kerja yang baik sesusai dengan panduankerja yang ditetapkan oleh perusahaan. Lingkungan Kerja Pada Outlat Indomaret Area Kota Depok dikatakan baik apabila lingkungan kerjanya sudah sesuai dengan standar panduan kerja yang telah ditetapkan agar bisa berjalan dengan 
optimal. Lingkungan kerja pada Outlet Indomaret Area Kota Depok masih banyak yang belum memenuhi standar, Seperti suhu udara, hal ini akan sangat mempengaruhi kinerja karayawan.

Selain lingkungan kerja untuk mendorong semangat kerja karyawan dibutuhkan adanya hubungan yang saling menguntungkan pada perusahaan. Karyawan memberikan prestasi yang baik untuk perusahaan, sedangkan perusahaan memberikan kompensasi yang sesuai atas prestasi kerja yang telah diberikan karyawan kepada perusahaan.

Pemberian kompensasi sangat penting bagi karyawan, karena besar kecilnya jumlah kompensai merupakan ukuran terhadap prestasi kerja karyawan, apabila sistem kompensasi yang diberikan perusahaan cukup adil dirasakan karyawan, maka akan mendorong karyawan untuk bekerja lebih baik dan bertanggung jawab atas masing - masing tugas yang diberikan oleh perusahaan.besarnya kompensasi atau bonus yang diberikan perusahaan masih belum sesuai dengan kinerja yang diberikan karyawan kepada perusahaan, oleh sebab itu kinerja karyawan tidak maksimal.

Kinerja merupakan bentuk perwujudan kerja yang optimal terhadap suatu perusahaan yang dilakukan oleh karyawan untuk menunjukkan suatu prestasi kerjanya, biasanya juga kinerja sangat erat hubungannya dengan masalahpenilaian kinerja itu sendiri.

Karyawan atau pegawai di suatuorganisasi atau perusahaan merupakan unsur yang penting karena karyawan atau pegawai sangat menentukan maju atau tidaknya perusahaan tersebut. Di dalam dunia bisnis, perusahaan sangat dituntut untuk menciptakan kinerja karyawan yang tinggi demi kemajuan perusahaan. Kinerja karyawan yang tinggi merupakan salah satu syarat dalam pencapaian visi dan misi perusahaan. Pencapaian visi dan misi tersebut tidak lain adalah dari mengelola sumber daya manusia yang berpotensi agar dapat meningkatkan hasil kinerjanya. Selain itu, dalam mengembangkan perusahaan dunia bisnis dan retail, saat ini dituntut untuk menerapkan manajemen sumber daya manusia yang baik dan menghasilkan karyawan yang berkualitas tinggi.

Namun dalam upaya menciptakan kinerja karyawan yang tinggi dan optimal, nampaknya masih terdapat berbagai masalah atau kendala yang membuat perusahaan sulit untuk mencapai tujuan dari perusahaan itu sendiri. Kendala yang timbul biasanya berasal dari dalam perusahaan itu sendiri dan berkaitan dengan karyawan. Masalah kinerja karyawan harus diatasi dengan baik karena baik buruk kinerja karyawan erat kaitannya dengan prestasi perusahaan itu sendiri.

periode 2019 tidak tercapai, dimana antara target sales sebesar Rp.5.414.818.800, sedangkan pencapaian sales hanya sebesar Rp.5.291.381.780 terdapat selisih -123.437.020. hal ini dikarenakan telah dibukannya gerai tiga kompetitor di sekitar lingkungan PT. INDOMARCO PRISMATAMA yang hanya berjarak \pm 50 meter dari PT. INDOMARCO PRISMATAMA.

Dengan demikian outlet Indomaret Area Kota Depok Sudah seharusnya memiliki Lingkungan Kerja yang nyaman dan kompensasi yang sesuai dengan kinerja yang diberikan karyawan kepada perusahaan agar mendapatkan hasil yang optimal. Maka dapat disimpulkan bahwa Lingkungan Kerja dan Kompensasi sangat berpengaruh terhadap kinerja karyawandalam berkerja dan memproleh hasil kerja, Tanpa adanya Lingkungan kerja dan Kompensasi yang baik maka kinerja pun tidak akan optimal begitupun sebaliknya apabila lingkungan kerja dan kompensasi terus ditingkatkan maka kinerja pun akan optimal. Kinerja karyawan erat kaitanya dengan hasil pekerjaan seseorang dalam suatu perusahaan, hasil kerja tersebut dapat berupa kualitas dan kuantitas. Kinerja karyawan tidak hanya dipengaruhi oleh kemampuan dan keahlian dalam berkerja tetapi juga sangat dipengaruhi oleh semangat kerja dan lingkungan kerja yang nyaman dan aman. 
Berdasarkan pemaparan diatas maka penulis tertarik ingin melakukan penelitian dengan judul "Pengaruh Lingkungan Kerja Dan Kompensasi Terhadap Kinerja Karyawan PadaPT. INDOMARCO PRISMATAMA Area Kota Depok".

\section{TINJAUAN PUSTAKA}

1. Manajemen Sumber Daya Manusia

Sumber Daya Manusia (SDM) dalam konteks bisnis, adalah orang yang bekerja dalam suatu organisasi yang sering pula disebut karyawan. Hasibuan (2006:39) meyatakan bahwa Manajemen Sumber Daya Manusia adalah ilmu dan seni mengatur hubungan dan peranan tenaga kerja agar efektif dan efesien dalam membantu terwujudnya tujuan perusahaan, karyawan dan masyarakat. Sedangkan menurut Simamora (2004:15) menyatakan: Manajemen Sumber Daya Manusia yaitu pendayagunaan, pemberian balas jasa dan pengelolaan individu atau kelompok pekerja.

2. Lingkungan Kerja

Anggoro \& Widiyanti (1993:31) lingkungan kerja adalah segala sesuatu yang ada disekitar karyawan dan yang dapat mempengaruhi dirinya dalam menjalankan tugas-tugas yang dibebankannya. Sedangkan menurut Sedarmayanti (2001:142-143) mengemukakan lingkungan kerja adalah sesuatu yang ada disekitar para pekerja dan yang mempengaruhi dirinya dalam menjalankan tugas-tugas yang dibebankan.

3. Kepuasan Kerja

Kepuasan kerja pada dasarnya merupakan sesuatu yang bersifat individual. Setiap individu memiliki tingkat kepuasan yang berbeda-beda sesuai dengan sistem nilai yang berlaku pada dirinya. Makin tinggi penilaian terhadap kegiatan dirasakan sesuai dengan keinginan individu, maka makin tinggi kepuasannya terhadap kegiatan tersebut. Jadi secara garis besar kepuasan kerja dapat diartikan sebagai hal yang menyenangkan atau yang tidak menyenangkan yang mana pegawai memandang pekerjannya. Hasibuan (2006:40). Kepuasan kerja adalah sikap emosional yang menyenangkan dan mencintai pekerjaannya. Sikap ini dicerminkanoleh moral kerja, kedisiplinan, dan prestasi kerja. Kepuasan kerjadinikmati dalam pekerjaan, luar pekerjaan, dan kombinasi antarakeduanya. Kepuasan kerja adalah keadaan emosional yang menyenangkan atau tidak menyenangkan dimana para karyawan memandang pekerjaan mereka. Kepuasan kerja mencerminkan perasaan seseorang terhadap pekerjaannya. Kepuasan kerja ini nampak dalam sikap positif karyawan terhadap pekerajaan dan segala sesauatu yang dihadapi di lingkungan kerjanya (Handoko, 2001:122).

4. Kompensasi

Pemberian kompensasi merupakan salah satu pelaksanaan fungsi MSDM yang berhubungan dengan semua jenis pemberian penghargaan individual sebagai pertukaran dalam melakukan tugas keorganisasian. Kompensasi adalah segala sesuatu yang diterima para karyawan sebagai balas jasa untuk kerja mereka (Handoko, 2001:123). Hasibuan (2006:42) menyatakan kompensasi diartikan sebagai semua pendapatan yang berbentuk uang, barang langsung atau tidak langsung yang diterima karyawan sebagai imbalan atas jasa yang diberikan kepada perusahaan.

5. Kinerja Karyawan

Mangkunegara

(2006:112) mendefinisikan kinerja karyawan adalah hasil kerja secara kualitas dan kuantitas yang dicapai oleh seseorang karyawan dalam melaksanakan tugasnya sesuai dengan tanggung jawab yang diberikan kepadanya. Simamora (2004:36) menyatakan kinerja mengacu kepada kadar pencapaian tugas- tugas yang 
membentuk sebuah pekerjaan karyawan. Kinerja merefleksikan seberapa baik karyawan memenuhi persyaratan sebuah pekerjaan. Kinerja seorang karyawan merupakan hal yang bersifat individual, karena setiap karyawan mempunyai tingkat kemampuan yang berbeda-beda dalam mengerjakan tugasnya. Pihak manajemen dapat mengukur karyawan atas unjuk kerjanya berdasarkan kinerja dari masing-masing karyawan.

\section{METODE}

Penelitian ini dilakukan pada PT. INDOMARCO PRISMATAMA, yang beralamatdi Jl. Kemang raya kampung cikumpa cilodong, Sukmajaya, Kota Depok 16414.

Penelitian ini dilakukan selama 3 (bulan) yaitu bulan Oktober sampai dengan Desember 2019. populasi dalam penelitian ini adalah seluruhkaryawan PT. INDOMARCO PRISMATAMA sebanyak 70 orang. Jadi sampel dalam penelitian iniadalah 70 responden.

Teknik Analisis Data

1. Analisis Regresi Linier Sederhana

2. Analisis Regresi Linier Berganda

3. Analisis Koefisien Korelasi (R)

4. Analisis Koefisien Determinasi (R Square) Pengujian Hipotesis

a. Uji Hipotesis Secara Parsial (Uji t)

b. Uji Hipotesis Secara Simultan(Uji F)

\section{HASIL DAN PEMBAHASAN}

Tabel 1. Analisis Regresi Linear Sederhana Hasil Pengolahan Regresi Sederhana Variabel Lingkungan Kerja (X1)

\begin{tabular}{|c|c|c|c|c|c|}
\hline \multicolumn{3}{|c|}{ UnstandardizedCoefficients } & \multirow{2}{*}{$\begin{array}{c}\text { Standardiz ed Coefficient s } \\
\text { Beta }\end{array}$} & & \multirow{2}{*}{ Sig. } \\
\hline Model & B & Std. Error & & & \\
\hline 1 (Constant) & 7.277 & 3.617 & & 2.012 & .048 \\
\hline Lingkungan Kerja & 848 & .083 & .780 & 10.278 & .000 \\
\hline
\end{tabular}

Berdasarkan hasil perhitungan tersebut maka dapat diperoleh persamaan regresi linear sederhana sebagai berikut: $\mathrm{Y}=$ 7,277+ 0.848X1Dimana X1 = Lingkungan KerjaY $=$ Kinerja Karyawan, Jika nilai $X=0$ akan diperoleh $Y=37,166$ Artinya nilai (a) atau konstanta sebesar7,277 nilai ini menunjukkan bahwa padasaat lingkungan kerja (X1) bernilai 0 atautidak meningkat,

Tabel 2. Hasil Pengolahan Regresi SederhanaVariabel Kompensasi (X2) \begin{tabular}{ll|l} 
UnstandardizedCoefficients StandardizedCoefficient sBeta & $t$ & Sig
\end{tabular}

\begin{tabular}{cc|l|l|r|r}
\multicolumn{1}{c}{ Model } & $\mathrm{B}$ & Std. Error & & \\
\hline 1 (Constant) & 37.166 & 5.720 & & 6.498 & .000 \\
\cline { 2 - 7 } Kompensasi & .165 & .132 & .150 & 1.250 & .215 \\
\cline { 2 - 6 }
\end{tabular}

Berdasarkan hasil perhitungan tersebut maka dapat diperoleh persamaan regresi linear sederhana sebagai berikut: $\mathrm{Y}=37,166+0.165 \mathrm{X} 2$

Dimana $\mathrm{X} 2=$ Kompensasi, $\mathrm{Y}=$ Kinerja Karyawan. Jika nilai $\mathrm{X}=0$ akan diperoleh $\mathrm{Y}$. Artinya nilai (a) atau konstanta sebesar37,166 nilai ini menunjukkan bahwa padasaat kompensasi (X2) bernilai 0 atau maka kinerja karyawan(Y) akan tetap bernilai 7,277 koefisienregresi nilai (b) sebesar 0.848 (positif) yaitu menunjukkan pengaruh yang searah yang artinya jika Lingkungan kerja ditingkatkan sebagai sebesar satu-satuan maka akan meningkatkan kinerja karyawan sebesar0.848 satuan. R 
Tabel 3. Analisis Regresi Linear Berganda Hasil Pengolahan Regresi Berganda Variabel Lingkungan Kerja (X1) dan Kompensasi (X2) Terhadap Kinerja Karyawan (Y)

\begin{tabular}{|c|c|c|c|c|c|}
\hline $\begin{array}{c}\text { Unstandardize } \\
\text { ModelB }\end{array}$ & Coeffi & $\begin{array}{l}\text { ients } \\
\text { Std. Error }\end{array}$ & Standar dized Coeffici entsBeta & $\mathrm{t}$ & Sig. \\
\hline 1Constant) & .146 & 5.000 & & -.029 & .977 \\
\hline Lingkungan Kerja & .849 & .081 & .781 & 10.545 & .000 \\
\hline Kompensasi & 171 & .081 & .155 & 2.096 & .040 \\
\hline
\end{tabular}

Berdasarkan hasil perhitungan regresi pada tabel diatas, diperoleh persamaan regresi $Y=0,146+0,849 \times 1+0,171 X 2$. Dari persamaan diatas maka dapat disimpulkansebagai berikut:

1. Nilai konstanta sebesar 0,146menyatakan bahwa jika nilai variabel Lingkungan Kerja (X1) dan Kompensasi (X2) tidak ada atau $=0$, maka nilai kinerja adalah sebesar 0,146 .
2. Koefisien

$$
\text { korelasi }
$$

Lingkungan

Kerja

mengandung

arti

(X1)

variable penambahan 1 (satu) poin variabel lingkungan kerja, maka hal itu meningkatkan kinerja sebesar 0,849 kali.

3. Koefisien korelasi variable Kompensasi (X2) 0,171 mengandung arti bahwa setiap penambahan 1 (satu) poin variabel Kompensasi, maka hal itu akan meningkatkan kinerja sebesar 0,171 kali.

Tabel 4. Uji Koefisien KorelasiHasil Analisis Koefisien KorelasiSecara Parsial VariabelLingkungan Kerja (X1) Terhadap Kinerja Karyawan (Y)

\begin{tabular}{ccccc}
\multicolumn{2}{c}{ Model R } & \multicolumn{2}{c}{ R Square } & AdjustedRSquareStd.Error ofthe Estimate \\
\hline 1 & $.780^{\mathrm{a}}$ & .608 & .603 & 2.850 \\
\hline
\end{tabular}

a. Predictors: (Constant), LingkunganKerja

Dari tabel diatas, diperoleh nilai berpengaruh Kuat yaitu sebesar 78\% koefisiensebesar 0,780 atau $78 \%$ maka dapat sisanya $22 \%$ dipengaruhi oleh faktor lain disimpulkan bahwa variabel Lingkungan diluar penelitian ini.

Kerja (X1) Terhadap Kinerja Karyawan (Y)

Tabel 5. Hasil Analisis Koefisien Korelasi Secara Parsial Variabel Kompensasi (X2) Terhadap

Kinerja Karyawan (Y)Model Summary

ModelR R Square AdjustedR Square Std.ErroroftheEstimate

\begin{tabular}{lll|l|l}
\hline 1 & $.150^{\mathrm{a}}$ & .022 & .008 & 4.503 \\
\hline
\end{tabular}

a. Predictors: (Constant), Kompensasi

Dari tabel diatas, diperoleh nilai koefisien korelasi sebesar 0,150 atau 15\% maka dapatdisimpulkan bahwa variabel kompensasi (X2) terhadap Kinerja

Karyawan (Y) berpengaruh lemah yaitu sebesar $15 \%$ sisanya $85 \%$ dipengaruhi oleh faktor lain diluar penelitian ini.

Tabel 6. Hasil Analisis Korelasi Secara Parsial Variabel Lingkungan Kerja (X1) Dan Kompensasi

(X2) Terhadap Kinerja Karyawan (Y)

Model Summaryb

Model R R Square AdjustedR Square Std.Error ofthe Estimate

\begin{tabular}{|c|c|}
\hline 1 & $95^{\mathrm{a}}$ \\
\hline
\end{tabular}

a. Predictors: (Constant), Kompensasi, Lingkungan Kerja

b.Dependent Variable: Kinerja

Dari tabel diatas, diperoleh nilai koefisiensebesar 0,795 atau $79,5 \%$ maka dapat disimpulkan bahwa variabel Lingkungan Kerja (X1) dan Kompensasi

(X2) Terhadap Kinerja Karyawan (Y) berpengaruh Kuat yaitu sebesar 79,5\% sisanya $20,5 \%$ dipengaruhi oleh faktor lain diluar penelitian ini. 
Tabel 7. Hasil Analisis Koefisien Determinasi Variabel Lingkungan Kerja (X1) dan Kompensasi

(X2) terhadap Kinerja Karyawan (Y)

Model R R Square AdjustedR Square Std.ErroroftheEstimate

Berdasarkan perhitungan pada tabel diatas, diperoleh nilai koefisien determinasi ( $\mathrm{R}$ - Square) sebesar 0,632, maka dapat disimpulkan bahwa Lingkungan Kerja (X1) dan Kompensasi (X2) secara bersama-sama Pengujian Hipotesis

1. Uji Parsial (t hitung)

Tabel 8. Hasil Uji t VariabelLingkungan Kerja(X1)

\begin{tabular}{cc|c|c|c|c}
\multicolumn{2}{c}{$\begin{array}{c}\text { Unstandardize dCoefficients } \\
\text { Model B }\end{array}$} & \multicolumn{1}{c|}{ Std. Error } & Standa rdized Coeffici entsBeta & $\mathrm{t}$ & Sig. \\
\cline { 2 - 7 } $\begin{array}{c}\text { 1(Constant) } \\
\text { Lingkungan Kerja }\end{array}$ & 7.277 & 3.617 & & 2.012 & .048 \\
\hline & .848 & .083 & .780 & 10.278 .000 \\
\hline
\end{tabular}

memiliki konstribusi pengaruh sebesar63,2\% terhadap Kinerja Karyawan $(\mathrm{Y})$, sisa nya 36,8\% dipengaruhi oleh faktor lain yang tidak diteliti.
Dari tabel diatas diperoleh nilai $\mathrm{t}$ hitung $>\mathrm{t}$ tabel $(10,278>1,664)$ dari nilai signifikan $0,000<0,005$ maka dapat disimpulkan Hditerima atau variabel Lingkungan Kerja(X1) secara parsial

Tabel 9. Hasil Uji t VariabelKompensasi

Coefficientsa

\begin{tabular}{|c|c|c|c|c|c|c|}
\hline & $\begin{array}{l}\text { andardizedCo } \\
\text { Model }\end{array}$ & B & Std. Error & Standardized CoefficientsBeta & $\mathrm{t}$ & Sig. \\
\hline 1 & (Constan $\mathrm{t})$ & 37.166 & 5.720 & & 6.498 & .000 \\
\hline & Kompen sasi & .165 & .132 & .150 & 1.250 & .215 \\
\hline
\end{tabular}

Dari tabel diatas, diperoleh nilai $t$ hitung $>\mathrm{t}$ tabel $(1,250>1,664)$ dari nilai signifikan0,000 < 0,05 maka dapat disimpulkan H2diterima atau variabel

Tabel 10. Uji F (uji serentak/simultan) Hasil Pengelolaan Data Pengujian F Simultan

$$
\text { ANOVAa }
$$

\begin{tabular}{|c|c|c|c|c|c|}
\hline \multicolumn{2}{|c|}{ SumofModel Squares } & df & MeanSquare & $\mathrm{F}$ & Sig. \\
\hline 1 Regres sion & 891.951 & 2 & 445.975 & 57.647 & $.000^{\mathrm{b}}$ \\
\hline Residu al & 518.335 & 67 & 7.736 & & \\
\hline Total & 1410.286 & 69 & & & \\
\hline
\end{tabular}

Dari tabel diatas diperoleh $\mathrm{F}$ hitung $=57,647>2,761$ atau (F hitung $>\mathrm{F}$ tabel)sehingga $\mathrm{H}$ ditolak dan $\mathrm{H}$ diterima. Artinya terdapat pengaruh positif dan simultan antara Lingkungan Kerja dan Kompensasi Terhadap Kinerja Karyawan.

\section{KESIMPULAN}

Hasil uji statistik $t$ dapat diketahui variabel Kualitas Pelayanan memiliki nilai $\mathrm{t}$ hitung 1,905 > t tabel 1,662. Hal ini berarti
Kompensasi (X2) secara parsial tidak berpengaruh terhadap Kinerja Karyawan (Y). secara parsial variabel Kualitas Pelayanan berpengaruh positif terhadap variabel Kepuasan Pelanggan, dan diperoleh hasil signifikan yang menunjukkan nilai 0,059 > 0,05 yang berarti terdapat pengaruh yang tidak signifikan antara Kualitas Pelayanan dan Kepuasan Pelanggan. Hal ini menunjukan bahwa Ho ditolak dan $\mathrm{H} 1$ diterima, artinya variabel Kualitas Pelayanan secara parsial berpengaruh positif dan tidak signifikan terhadap 
Kepuasan Pelanggan. Sehingga, jika nilai Kualitas Pelayanan yang diterima pelanggan naik maka Kepuasan Pelanggan akan meningkat.

Hasil uji statistik $\mathrm{t}$ dapat diketahui variabel Kualitas Produk memiliki nilai $\mathrm{t}$ hitung 8,772 > t tabel 1,662 dengan nilai signifikan $0,000<0,05$. Hal ini menunjukkan bahwa Ho ditolak dan $\mathrm{H} 2$ diterima artinya variabel Kualitas Produk secara parsial berpengaruh positif dan signifikan terhadap Kepuasan Pelanggan. Sehingga, jika nilai variabel Kualitas Produk naik maka Kepuasan Pelanggan akan meningkat.

Hasil uji statistik F (simultan), dapat diketahui bahwa nilai F-hitung 167,955 > Ftabel 3,08. Maka dapat disimpulkan bahwa Ho ditolak dan $\mathrm{H} 3$ diterima. Hal ini berarti variabel Kualitas Pelayanan dan Kualitas Produk secara simultan berpengaruh positif dan signifikan terhadap Kepuasan Pelanggan PT. Iwatani Industrial Gas Indonesia Wilayah Pemasaran Cikupa Tangerang.

\section{DAFTAR PUSTAKA}

Abil Fauzan Arifki dan Fullchis Nurtjahjani. (2018). Pengaruh Kualitas Produk dan Kualitas Pelayanan Terhadap Kepuasan Konsumen Pada Alfabeth Store Pasuruan. Jurnal Aplikasi Bisnis (JAB) .Vol.4 No.1 Juni 2018. ISSN 2407 3741.E-ISSN 24075523.

Abubakar. Rusydi. (2017). Manajemen Pemasaran. Bandung. Penerbit: Rineka Cipta.

Akbar, I. R. (2020). Pengaruh Kompensasi Dan Etos Kerja Terhadap Komitmen Organisasi Pada Pt. Central Buana Mandiri. Value: Jurnal Manajemen dan Akuntansi, 15(1), 73-80

Alma. Buchari. (2015). Manajemen Pemasarandan Pemasaran Jasa. Bandung. Penerbit CV. Alfabeta.

Andrew E. Sikula. (2015). Manajemen Sumber Daya Manusia. Bandung: Erlangga.

Asep Sulaeman. (2018). Pengaruh Kualitas Pelayanan dan Kualitas Produk Terhadap Kepuasan Pleanggan (Studi Pada PT Cakrawala Citramega). KREATIF.Jurnal
Ilmiah Prodi Manajemen Universitas Pamulang. Vol. 6, No.1, Januari 2018, ISSN: 2339-0689, E-ISSN: 24068616.

Danang. Sunyoto. (2015). Perilaku Konsumen dan Pemasaran. Yogyakarta. CAPS (Center For Academic Publishing Service).

Effendy, A. A., Sunarsi, D., Kristianti, L. S., Irawati, L., \& Wahyitno, W. (2020). Effect Of Giving Reward and Motivation to Employee Productivity In PT. Sinar Kencana Jaya In Surabaya. HUMANIS (Humanities, Management and Science Proceedings), 1(1).

Fandy. Tjiptono dan Chandra. (2016). Serivce Quality and Satisfiation. Jakarta.Edisi Tiga. Andi.

Farah Diza, Sileyjeova dan Imelda W.J Ogi. (2016). Pengaruh Kualitas Pelayanan, Kualitas Produk Dan Kepercayaan Terhadap Kepuasan Komsumen (Studi Kasus Pada PT. FIFGROUP Cabang Manado). Jurnal EMBA. Volume 4 No. 1, Maret 2016. ISSN : 23031174.

Geraldy Tambajong. (2013). Bauran Pemasaran Pengaruhnya Terhadap Penjualan Sepeda Motor Yamaha Pada PT. Sarana Niaga Megah Kerta Manado. Jurnal EMBA, Vol.1 No.3 September 2013, Hal. 1291-1301.

Ghozali. Imam. (2016). Aplikasi Analisis Multivariate dengan Program SPSS 23.Semarang. Badan Penerbit Undip.

Hasan. Ali. (2013). Marketing dan Kasus Kasus Pilihan. Yogyakarta: CAPS (Center For Academic Publishing Service).

Hasibuan. Malayu S.P. (2017). Manajemen Sumber Daya Manusia. Edisi Ke Delapanbelas. Jakarta : Bumi Aksara.

Husen. Umar. (2013). Riset Pemasaran Dan Perilaku Konsumen. PT. Gramedia Pustaka Utama. Jakarta.

Keller dan Amstrong. (2016). Marketing Management. Edisi Ke Limabelas. Pearson Education.Inc.

Kotler. \& Amstrong . (2015). Principles of Marketing. Edisi: Kesembilan Belas .Jakarta : PT. Indeks . 
Linda Suprihatin, Denok Sunarsi. (2021). Pengaruh Kepemimpinan Transaksional dan Lingkungan Kerja Terhadap Kinerja Pegawai di Pusat Pendidikan dan Pelatihan Pegawai Kementerian Pendidikan dan Kebudayaan. JIIP-Jurnal Ilmiah Ilmu Pendidikan. Volume 4. Issue 1. Pages 78-86.

Lupiyoadi. Rambat. (2014). Manajemen Pemasaran Jasa. Jakarta: Salemba Empat.

Malik Ibrahim dan Sitti Marijam Thawil. (2019). Pengaruh Kualitas Produk Dan Kualitas Pelayanan Terhadap Kepuasan Pelanggan (Studi Kausu Pada PT MNC Vision Tbk). Jurnal JRMB UNIAT. Vol. 4 No. 1 Februari 2019. P-ISSN: 25277502 E-ISSN: 2581-2165.

Moleong, Lexy J. (2016). Metode Penelitian Kualitatif. Edisi Revisi. Bandung: PT. Remaja Rosdakarya.

Mullins, John W dan Walker Jr, Orville C. (2013). Marketing Management: A Strategic Decision-Making Approach. 8th Edition. Mc Graw-Hill International Edition.

Nurjaya, N., Sunarsi, D., Effendy, A. A., Teriyan, A., \& Gunartin, G. (2021). Pengaruh Etos Kerja Dan Disiplin Kerja Terhadap Kinerja Pegawai Pada Dinas Kehutanan Dan Perkebunan Kota Bogor. JENIUS (Jurnal Ilmiah Manajemen Sumber Daya Manusia), 4(2), 172-184.

Nurmin Arianto. (2016). Pengaruh Kualitas Produk Dan Harga Terhadap Keputusan Pembelian Air Minum Dalam Kemasan (Amdk) Merek Aqua. KREATIF.Jurnal
Prasada, D., Sunarsi, D., \& Teriyan, A. (2020). Pengaruh Etos Kerja Dan Kompensasi Terhadap Komitmen Organisasi Pada DHL Logistic Di Jakarta. JENIUS (Jurnal Ilmiah Manajemen Sumber Daya Manusia), $4(1), 51-60$.

Sekaran. Uma dan Roger Bougie. (2017). Metode Penelitian untuk Bisnis: Pendekatan Pengembangan-Keahlian. Edisi 6. Buku 1. Cetakan Kedua. Jakarta. Salemba Empat.

Sofyan, S., Prasada, D., \& Akbar, I. R. (2020). Pengaruh Motivasi, Lingkungan Kerja dan Kepuasan Kerja Terhadap Kinerja Guru SMP/MTs Muhammadiyah Cabang Sawangan. Jurnal Ilmu Komputer dan Bisnis, Volume 11, Issue 2a, Pages 44-55

Sudarsono. Heri. (2016). Bank dan Lembaga Keuangan Syariah. Edisi Keempat. Yogyakarta. Penerbit: Ekonisia.

Sugiyono. (2015). Metode Penelitian Kuantitatif Kualitatif dan $R \quad \mathcal{E} D$. Bandung. Penerbit CV. Alfabeta.

Sugiyono. (2017). Metode Penelitian Kualitatif: Untuk Penelitian yang bersifat Eksploratif, enterpretif, interaktif, dan konstruktif. Bandung. Penerbit CV. Alfabeta.

Sunarsi, D., Akbar, I. R., Rozi, A., Khoiri, A., \& Salam, R. (2021, January). The Influence of Motivation and Work Discipline on Employee Performance at the Yogyakarta Tourism Service. In Proceeding The First International Conference on Government Education Management and Tourism (Vol. 1, No. 1, pp. 1-7). 